\title{
Endogenous governance transparency and product market competition
}

\author{
Ana Hidalgo-Cabrillana
}

Received: 29 January 2010 / Accepted: 21 November 2011 / Published online: 3 December 2011 (C) The Author(s) 2011. This article is published with open access at SpringerLink.com

\begin{abstract}
This paper analyzes the determinants of governance transparency. In our model, entrepreneurs optimally decide the precision of their earning reporting by trading off the possibility of expropriating profits against the capacity to attract external funding. We find that information is only valuable if enough quality of it is disclosed. Otherwise, the entrepreneur will always pretend to be unsuccessful and the capital market will break down. If, by contrast, a minimum precision level is ensured, fund diversion will be zero but full disclosure is still not achieved. We show that an important driving force behind governance transparency is product market competition. Tougher competition leads to more firms competing for funding, which in turn changes how resources are allocated since each individual firm becomes less important in the portfolio choice. Firms react to this loss of market power by increasing transparency. Furthermore, firms characterized by low corporate profits or firms in a country with a strong legal system will be more likely to avoid voluntary disclosure regimes.
\end{abstract}

Keywords Corporate governance - Voluntary disclosure - Portfolio choice • Incentives · Product market competition

\footnotetext{
I would like to thank Piergiuseppe Fortunato, the editor and anonymous referees for their insightful comments and suggestions, as well as participants of the seminars and conferences held at the Universidad Autónoma de Madrid, Universidad Carlos III de Madrid, the SAE in Zaragoza, the EEA-ESEM in Budapest, and the PET in Nashville. The author gratefully acknowledges the hospitality of the Economics Department at Columbia University where part of this work was conducted, as well as the Spanish Ministry of Science and Innovation for their financial support through ECO2010-19596. All errors are mine.
}

A. Hidalgo-Cabrillana $(\bowtie)$

Department of Economic Analysis: Economic Theory and History, Universidad Autónoma de Madrid, Madrid, Spain

e-mail: ana.hidalgo@uam.es 
JEL Classification $\quad \mathrm{D} 82 \cdot \mathrm{G} 11 \cdot \mathrm{G} 32 \cdot \mathrm{G} 34$

\section{Introduction}

Due to the emerging market crisis of the 1990s and recent corporate governance and accounting scandals, the desirability of disclosure requirements has long been a major subject of debate among policymakers and academics. However, there is no agreement on the optimal level of financial accounting information and its regimes vary widely around the world. At one extreme, much of the literature is skeptical about the need for compulsory transparency — except perhaps in the extreme case of market failurebecause market forces will generally ensure the optimal level of information. At the other extreme, it is often argued that a higher level of financial accounting increases market liquidity and firm valuation. ${ }^{1}$ However, we do not observe firms providing full disclosure. We therefore need to gain a better understanding of the variables affecting the transparency of corporate reporting.

This paper tackles an important area of corporate governance: the determinants of voluntary governance transparency. To this end, we develop a theoretical model of corporate transparency, treating governance disclosure as an endogenous variable and assuming that entrepreneurs control the precision of the information available to outside investors. The model is used to address the following kinds of research questions: (i) With regard to the factors affecting disclosure: Why do firms engage in voluntary transparency? How does product market competition affect voluntary disclosure? (ii) With regard to the governance role of publicly reported financial accounting information: What is the relation among publicly reported financial accounting information, corporate governance, and management incentives? (iii) With regard to the economic consequences of disclosure for financial markets: How do investors respond to corporate disclosures? That is, how does disclosure affect resource allocation in the economy? Is disclosure necessary for the functioning of the capital market?

The scenario we consider assumes that entrepreneurs have no wealth and need capital from investors to carry out a risky project. Both are symmetrically informed when they enter into a contractual agreement. After contracting, however, firms are better informed than outside investors on the project's realization: the former know the returns realized, whereas the outside investors only observe a signal of these returns. The precision of this signal is our measure of governance transparency. Since entrepreneurs have more information, they can divert funds at the expense of firm value. Because of this, investors offer a contract to entrepreneurs that is designed to limit the level of expropriation. The contract, which is contingent on the firms's report-and thus on all observable variables, including the precision of the signal-is defined by the amount of capital that investors put into the firm as well as by a payment made by investors to entrepreneurs. The contract endogenously determines the central trade-off for the entrepreneur when deciding the optimal level of transparency because better quality of information decreases the possibility of expropriation against the capacity to attract external funding.

\footnotetext{
${ }^{1}$ See Leuz and Wysocki (2008) for an analysis on the capital market outcome of disclosure.
} 
The model is based on the following three key assumptions. First, we develop the model in a setting with product market competition. Second, outside investors are risk averse and rationally formulate their asset allocations and consumption-saving decisions. Third, the information disclosed by the firm needs to be verifiable. Because firms have incentives to disclose self-serving information, it is unclear whether increased transparency actually reflects credible information. In practice, there are two potential ways to increase the credibility of voluntary disclosure. Investors can write an ex-ante contract with a third-party who can provide assurance about the quality of the firms' disclosures. Alternatively, firms can be taken to court ex-post by investors. This study focuses on the second mechanism. ${ }^{2}$

We find that low quality information does not have much value, and information is only valuable if enough quality of it is disclosed. That is, to incentivize a legal action, investors need a certain threshold level of quality of information, otherwise, the entrepreneur will always pretend to be unsuccessful and the capital market will break down. If, by contrast, a minimum precision level is ensured, the optimal level of disclosure enhances its governance role since, in equilibrium, entrepreneurial funds diversion is zero but full disclosure does not prevail. Therefore, transparency becomes the solution to the agency problem, and the entrepreneur will voluntarily choose a strictly positive but far from perfect level of disclosure even though, ex-post, he prefers opacity as it allows him to divert cash flows.

In addition to this, we find a closed-form solution to the optimal level of transparency. Consequently, our theory indicates the driving forces of voluntary transparency and helps us predict which firms are likely to engage in strategies to avoid a proposed regulation. The model delivers the following predictions.

First, we find that a more competitive environment increases the quality of financial accounting information through a change in the optimal portfolio of investors. The greater the number of firms in the product market, the more firms competing for funding. This, in turn, changes how resources are allocated in the economy because investors adjust their portfolio choices. Specifically, investors like to diversify risk and each individual firm becomes less important in the portfolio choice. As a result, each entrepreneur has less market power, and is forced to make the concession of offering high governance transparency.

Second, we find that a weak legal system or regime (i.e., lower penalties in the case of being taken to court) increases voluntary disclosure. This is the case since when courts are weaker, the only way that firms will be able to persuade outsiders to invest is by practicing stronger transparency.

Third, we find that better governance transparency may be driven by higher corporate profits. Under higher profits, the agency problem is more severe because entrepreneurs have stronger incentives to divert profits, forcing them to impose ex-ante stricter governance disclosure mechanisms as a commitment device to prevent ex-post expropriation. This result provides a rationale for higher regulation in an economic upturn.

The next section places this study in the context of the existing literature. After presenting the model in Sect. 3, we derive the optimal contract in Sect. 4. Section 5

\footnotetext{
2 For a discussion of the literature using the first mechanism see Sect. 4.3.
} 
completes the paper with a discussion of the intended contribution, the limitations of this study, and opportunities for future research. The Appendix contains all the omitted proofs.

\section{Relation to the existing theoretical literature}

This paper is related to the growing body of literature analyzing governance disclosure at the firm level as well as the literature on corporate governance in competitive settings.

Concerning the first branch of the literature, the papers most closely related to the present one are those of Song and Thakor (2006) and Hermalin and Weisbach (2008). Song and Thakor (2006) recognize that the CEO controls the information seen by the board. However, they introduce career concerns on the part of the board and CEO, and these interact with each other. ${ }^{3}$ In their model, the CEO's expected utility is the sum of firm value and career concerns, which are functions of how either the board or the shareholders perceive the CEO's ability level. Hermalin and Weisbach (2008) consider the effect of optimal disclosure rules, which are controlled by the principal. When determining optimal disclosure, the principal trade-off is that whereas higher disclosure allows for better monitoring of management, it can also increase managerial compensation, and distortions in managerial behavior. While the two models and their objectives differ, there is a common finding indicating that, due to career concerns, CEOs try to affect how they are evaluated, either by decreasing disclosure or by taking actions that can distort owner's information. Another important contribution dealing with disclosure is that of Adams and Ferreira (2007), whose model focuses on different issues than the present paper: namely, the implications of the board's dual roles in advising and monitoring the firm's management. ${ }^{4}$

We extend and complement the existing literature in several ways. First, the previous work on governance disclosure has ignored the issue of contracts. In a setting of information asymmetries, we introduce entrepreneurial funds diversion instead, and concentrate on agency problems between firms and investors. In the theory proposed here, parties write contracts, and we analyze the implications of this contracting for the optimal level of firm transparency, for entrepreneurial incentives to misbehave, and for resource allocation in the economy. Second, since we derive disclosure rules endogenously and based on profit-maximizing rules, this allows us to understand the factors shaping the quality of information reported by firms. In particular, this paper expands the conflicting literature on corporate governance and competition by explaining a new channel through which product market competition may affect governance transparency.

The common wisdom from the literature dealing with corporate governance is that product market competition can impose discipline on a firm's management. Competition between different firms may help to limit losses as well as levels of expropriation.

\footnotetext{
3 By career concerns they mean the perception of how the agent's human capital is valued by the market since it determines retention and compensation decisions.

4 Similarly, Admati and Pfleiderer (2000) analyze a model of voluntary disclosure by firms in the context of positive externalities in the form of information transfers.
} 
As a result, economies with a high level of competition are characterized by a strong level of corporate governance (see Allen and Gale 2000; Hart 1983; Stigler 1958; Vives 2000, among others). However, as Holmström and Tirole $(1989,97)$ point out "apparently, the simple idea that product market competition reduces slack is not as easy to formalize as one might think." Indeed, Scharfstein (1988) introduces more general preferences to the framework proposed by Hart (1983), and finds that competition actually increases slack. We reach the conclusion that tougher competition increases the quality of financial accounting information through a different channel: by adjusting the investor's portfolio choices. We are not aware of any paper to date that explicitly states this precise channel.

Equally importantly, it should be noted that our theory opens the door for a new line of research on empirical issues in governance transparency, in which the new mechanism should be tested and control variables proposed to examine the determinants of firm-level governance disclosure. Although the evidence supports the arguments advanced here, more research is needed to further support the importance of our theory.

\section{The model}

The economy is described by a two-period model and is populated by two types of agents: entrepreneurs and a representative investor. Since entrepreneurs have no capital endowment, they have to raise money on financial markets to exploit the potential production possibilities. The investor, on the other hand, is endowed with capital. Capital markets are subject to imperfections arising from the non-observability of output for financiers, and formal contracting arrangements are adopted to amend these frictions.

\subsection{The set up}

\subsubsection{Entrepreneurs}

Consider a framework with $N$ firms - also called entrepreneurs-which are risk neutral and without initial wealth, but endowed with a risky project. The riskiness arises from the fact that only one firm pays off and thus $k_{t}^{i}$ units of capital invested in firm $i$ will return the next period to firm $i$ either $R N k_{t}^{i}$ with probability $\frac{1}{N}$, or nothing with probability $1-\frac{1}{N}$, with $i=1, \ldots, N$. That is, the payoff from the investment in each firm takes the values $\{R N, 0\}$.

We have rescaled $R$ according to $N$ to keep the average profitability of the project constant. Therefore, increasing $N$ will increase competition and will only affect the risk since it makes success more difficult. ${ }^{5}$ We attempt to capture the general belief supported in the theoretical and empirical literature that competition is a key

\footnotetext{
5 Giroud and Mueller (2010) show empirically that an increase in competition reduces a firm's profits. In our model, competition does not translate into a direct reaction to a fall in profits but the analysis is robust to the alternative specification of competition affecting both risk and expected profits (see a previous version of the paper at http://e-archivo.uc3m.es/bitstream/10016/9340/1/we10-21.pdf).
} 
Table 1 The binary signal (model)

\begin{tabular}{lll}
\hline & $R_{H}=R N$ & $R_{L}=0$ \\
\hline$s=s_{H}$ & $p^{i}$ & $1-p^{i}$ \\
$s=s_{L}$ & $1-p^{i}$ & $p^{i}$ \\
\hline
\end{tabular}

mechanism threatening the survival of the firm since with a large number of firms only the more efficient ones - only one in our model-will survive. ${ }^{6}$

Entrepreneurs must obtain funds from investors to finance the project and contracting arrangements are adopted between them. As we will see in detail, the contract consists in the amount of investment made in firm $i$, i.e. $k_{t}^{i}$ and a transfer, which is contingent on the firm's report, paid by the investor to firm $i$.

\subsubsection{Information structure}

From the point of view of a single firm, the output realization per unit of capital invested is either $R N$ or 0 , and the success probability is $\frac{1}{N}$. Although the probability distribution is common knowledge to all agents in the economy, its realizations are private information to the firms. The representative investor, on the other hand, receives a private binary symmetric signal $s$ with two possible values: high or low and with the probabilities given in Table 1 .

The symmetry of the signal does not restrict the generality of the analysis and simplifies the exposition. When the signal is symmetric, by convention $p^{i} \in\left[\frac{1}{2}, 1\right]$, so that when the return is high we have $p\left(s_{H} / R_{H}\right)=p^{i}$, while when the return is low we have $p\left(s_{L} / R_{L}\right)=1-p^{i}$. Let $\frac{1}{N}$ and $1-\frac{1}{N}$ be the prior probability of a high and low state of nature, respectively, for an investor with no private signal. An agent endowed with a signal $s$ updates this probability using Bayes' rule, so that, conditional on receiving a high signal, the posterior probability becomes,

$$
p\left(R_{H} \mid s_{H}\right)=\frac{p\left(s_{H} \mid R_{H}\right) p\left(R_{H}\right)}{p\left(s_{H} \mid R_{H}\right) p\left(R_{H}\right)+p\left(s_{H} \mid R_{L}\right) p\left(R_{L}\right)}=\frac{p^{i} \frac{1}{N}}{p^{i} \frac{1}{N}+\left(1-p^{i}\right)\left(1-\frac{1}{N}\right)},
$$

and $p\left(R_{L} \mid s_{H}\right)=1-p\left(R_{H} \mid s_{H}\right)$. And conditional on receiving a low signal, the update forecast is

$$
p\left(R_{H} \mid s_{L}\right)=\frac{p\left(s_{L} \mid R_{H}\right) p\left(R_{H}\right)}{p\left(s_{L} \mid R_{H}\right) p\left(R_{H}\right)+p\left(s_{L} \mid R_{L}\right) p\left(R_{L}\right)}=\frac{\left(1-p^{i}\right) \frac{1}{N}}{\left(1-p^{i}\right) \frac{1}{N}+p^{i}\left(1-\frac{1}{N}\right)},
$$

and $p\left(R_{L} \mid s_{L}\right)=1-p\left(R_{H} \mid s_{L}\right)$.

\footnotetext{
6 Mata et al. (1995) empirically examine the factors that influence the probability of a firm's survival on the market and show that market size is an important determinant of firm success. Similarly, Guadalupe and Pérez-González (2006) find that a higher default probability is associated with tougher competition.
} 
Under perfect information, it will be either $p^{i}=1$ or $p^{i}=0$, while the signal conveys no information about the realization of the project when $p^{i}=\frac{1}{2}$. Clearly, the parameter $p^{i}$ measures the precision of the signal and is a variable of crucial interest. The better the quality of the signal received by the investor, the easier it will be to protect herself from attempts at expropriation by some of the firms. This is the reason why we take the quality of this signal as an indicator of the quality of governance transparency. In particular, we will show that contracting arrangements endogenously determine how the firms decide about the degree of voluntary governance disclosure, i.e. the value of $p^{i}$, by trading-off the benefit of attracting more capital against the possibility of expropriating profits.

\subsubsection{The representative investor}

The inclusion of investors in the model will provide a better understanding of how investors allocate resources in the economy, how they respond to corporate disclosures and if disclosure practices are necessary for the functioning of capital markets.

The investor is concerned about consumption, saving, and portfolio choice decisions. We assume she is risk averse with the following Cobb-Douglas specification of the utility function,

$$
U_{t}=c_{t}^{1-\alpha} c_{t+1}^{\alpha},
$$

where $c_{t}$ is the amount consumed in period one, and $c_{t+1}$ is consumption in period two. In the first period, the available resources $\bar{K}$, can be used either to consume or to invest, and thus the budget constraint is

$$
c_{t}+\sum_{i=1}^{N} k_{t}^{i}=\bar{K},
$$

where $k_{t}^{i}$ is the amount invested in firm $i$, and thus $\sum_{i=1}^{N} k_{t}^{i}$ is the total amount of resources invested in all $N$ firms. In the second period, the budget constraint is $c_{t+1} \leq$ $y_{t+1}$, with $y_{t+1}$ being the investor's income coming from the payoff of the diversified portfolio, that is

$$
y_{t+1}=R^{c} k_{t}^{i}-w^{i}\left(R^{c}\right),
$$

with $R^{c} \in\{R N, 0\}$ and the superscript $c$ referring to firm's claim, and $w^{i}$ being the equilibrium transfer that the investor pays to firm $i$. In Sect. 4 we will show how this transfer is determined in the equilibrium contract. Not surprisingly, it will be contingent on the firm's report and all observables-including $p^{i}$.

In practice, investors have difficulties accessing whether information is credible. Although investors may have strong incentives to detect fraud, they do not always act accordingly because they have inferior access to information. For this reason, we introduce courts whose task is to collect and assess information that can lead to the detection of fraud. We consider credibility issues in the simplest way as a small, preliminary step toward a comprehensive theory as future research. 
The investor decides whether to go to court or not on the basis of the signal and the firm's report. Investors could derive benefits from taking the entrepreneur to court because, if found guilty, the entrepreneurs will have to give back the hidden returns, i.e. $[R N-0] k_{t}^{i}$. However, accessing court is also costly. To simplify the math, we assume that this cost is proportional to the recovery of hidden output, i.e. $\phi[R N-0] k_{t}^{i}{ }^{7}$ If taken to court by outside investors and found guilty of fraud, entrepreneurs, apart from giving back the hidden returns, will also be obligated to pay a penalty cost which is proportional to the capital invested in the project, i.e. $F k_{t}^{i} .{ }^{8}$ Notice that, unlike the hidden returns, which are given back to investors if the entrepreneur is guilty, both the entrepreneurs' and the investors' court fees are deadweight cost and thus no one gets them.

The exogenous parameters $F$ and $\phi$ represent the strength of the country's legal system. Indeed, the larger the $F$, the more rigorously the country's antifraud law is enforced and likewise, a smaller accessing $\operatorname{court} \operatorname{cost} \phi$ would imply a more developed country's legal system. ${ }^{9}$

\subsubsection{Timing}

Contracting takes place in the ex-ante stage, that is, before the realization of the output is known. In the first period, entrepreneurs are endowed with a project. Each firm chooses the level of transparency, and goes to the capital market announcing simultaneously its $p^{i}$ and asking for financial needs. Next, the representative investor, who is endowed with $\bar{K}$ units of capital, offers a contract to each firm. The contract, which is contingent on the firm's report, consists of the amount of investment made in the firm $k_{t}^{i}$ and a contingent transfer $w^{i, h}, w^{i, l}$ paid by the investor to the firm. After that, each firm either accepts the contract and borrows $k_{t}^{i}$ to establish the firm, or rejects the contract.

At the outset of the second period, a firm produces output equal to either $R N k_{t}^{i}$ or 0 . This realization is private information for the entrepreneurs, who have the option of hiding some of their cash flows from their financiers. The investor, by contrast, receives a private signal with the probabilities distribution given in Table 1 . Once the project is realized, the firm makes a claim about its realization $R^{c} \in\{R N, 0\}$, where the superscript $c$ refers to the firms' claim, and the contract is satisfied. That is, the firms give the investor the intermediary output consistent with the claim (i.e. $R N k_{t}^{i}$ or 0 ) and receive a contingent transfer.

Based on the private signal and the claim, the representative investor then decides whether or not to go to court, but going to court is costly for her. Courts, which are modeled in a reduced form, have the role of collecting the information that might lead to the detection of fraud, and acting upon it accordingly. If the entrepreneur is lying, the court will surely find him guilty, the entrepreneur must pay the penalty $F k_{t}^{i}$ and will also be forced to pay the representative investor her due returns.

\footnotetext{
7 Assuming a fixed cost of going to court, the results hold too.

8 The assumption of a proportional penalty cost is useful when solving the investor's portfolio allocation. It allows us to have a closed-form solution of the model.

${ }^{9}$ Easy access to courts by shareholders is commonly viewed as an important element of a good corporate governance system. For recent evidence on reforms encouraging shareholders suits see Enriques and Volpin (2007).
} 
If the project is of low quality, entrepreneurs end up with income $y_{i, t+1}=w^{i, l}$. Without an endowment, the entrepreneur is unable to misreport in the low state, since this would entail a level of output $R N k_{t}^{i}>0$. If the returns are high, truthful reporting yields $y_{i, t+1}=w^{i, h}$, and concealing yields $y_{i, t+1}=w^{i, l}+[R N-0] k_{t}^{i}=w^{i, l}+R N k_{t}^{i}$. That is, by misreporting the entrepreneur receives the transfer intended for low return projects plus the hidden output. If, however, the investor decides to go to court and the firm is lying, the entrepreneur's income becomes $y_{i, t+1}=w^{i, l}+R N k_{t}^{i}-F k_{t}^{i}-R N k_{t}^{i}$. The last two terms are the total cost imposed on the entrepreneur if lying (i.e. if the entrepreneur reported low returns under a high returns realization): the entrepreneur must pay the penalty $F k_{t}^{i}$ as well as the confiscation of $R N k_{t}^{i}$.

As we will see later on, the equilibrium contract always requires the output surrendered to be consistent with the report. This implies no hiding along the equilibrium path. We will solve the model using the standard backward induction: after studying the optimal decision of the investor as to go to court or not, characterizing the optimal transfer, and analyzing the investor's portfolio decision, we will study the firm's choice regarding the design of governance transparency.

\section{The equilibrium contracts}

The dominant entrepreneur's strategy-independently of the returns realized-is to claim low returns because in this way he can lie and steal some positive amount of profits. Given that the entrepreneur has no cash, it is impossible for him to claim a high cash flow realization when the actual realization is low. ${ }^{10}$ Therefore, the entrepreneur's strategy of claiming high returns is implicitly self-revealing and, given that accessing court is costly for investors, it is useless to go to court. As a result, the representative investor would decide to go to court iff the report were a low one.

According to the timing, once returns are realized, and the contract is executed, investor observes $s$ and decides whether or not to go to court. ${ }^{11}$ The investor will always face a trade-off between paying the costs in the hopes of recovering part of the returns, and not doing so. If the court costs are high enough to discourage legal action when the signal is low, but low enough to incentivize legal action when the signal is high, the investor will optimally minimize the decision to go to court and will use the court option only if the claim is low and the signal is high. This would happen under assumptions $\mathrm{A} 1$ and $\mathrm{A} 2$ below.

If the signal is high, with probability $p\left(R_{H} / s_{H}\right)$, the returns are going to be high. If the entrepreneurs' claim were low and the investor goes to court, the entrepreneur

\footnotetext{
10 Following Innes (1990), the investor's payoffs are going to be increasing in the reported returns-as stated in the proof of Proposition 1. Under this monotonicity constraint, entrepreneurs would never engage in arbitrage activities. Specifically, entrepreneurs would never revise their profits report upward by borrowing money temporarily and this borrowing being undetected.

11 The model is robust to a slight change in the timing. Specifically, we could assume that the events were as follows: first, the entrepreneurs make a claim and output is surrendered accordingly. After that, investors decide whether to go to court or not. Consistent with the court decision, the investor will give the transfer to the entrepreneur and the entrepreneur will give back the diverted output to investors if they were lying.
} 
is found guilty and the investor income is $y_{t+1}=R N(1-\phi) k_{t}^{i}-w^{i, l}$. That is, the investor receives the output surrendered consistent with the low claim, i.e. zero, and the entrepreneur receives the transfer intended for a low return $w^{i, l}$. Moreover, the hidden output is recovered but the cost of accessing court needs to be paid, i.e. $R N(1-\phi) k_{t}^{i}$. However, with probability $p\left(R_{L} / s_{H}\right)$, the investor goes to court and since the claim coincides with the returns, the entrepreneur was telling the truth. Investor income is $y_{t+1}=-\phi R N k_{t}^{i}-w^{i, l}$. All in all, when the investor is endowed with a high signal, she will decide to go to court iff the expected net profits are strictly positive, that is

$$
\begin{aligned}
& p\left(R_{H} / s_{H}\right)\left(R N k_{t}^{i}(1-\phi)-w^{i, l}\right) \\
& \quad \geq p\left(R_{L} / s_{H}\right)\left(\phi R N k_{t}^{i}+w^{i, l}\right) \Longleftrightarrow p^{i} \geq \frac{\phi(N-1)}{(1-\phi)+\phi(N-1)} .
\end{aligned}
$$

To obtain the last inequality, first we have substituted the posterior probabilities given in Eqs. (1) and (2), and second, we have imposed $w^{i, l}=0$. As explained in Sect. 4, since under a low state of nature the output is zero and limited liability is assumed, the equilibrium transfer upon a low realization will be zero too.

If the investor is endowed with a low signal, the posterior probability of having a high return and a low return are $p\left(R_{H} / s_{L}\right)$ and $p\left(R_{L} / s_{L}\right)$, respectively. In the first case the entrepreneur is lying since his claim was low and the investor income of going to court is $y_{t+1}=R N k_{t}^{i}(1-\phi)-w^{i, l}$, but in the second he is telling the truth with the investor income being $y_{t+1}=-\phi R N k_{t}^{i}-w^{i, l}$. The investor will decide not to go to court if the expected net profits are such that

$$
\begin{aligned}
& p\left(R_{H} / s_{L}\right)\left(R N k_{t}^{i}(1-\phi)-w^{i, l}\right) \\
& \quad \leq p\left(R_{L} / s_{L}\right)\left(\phi R N k_{t}^{i}+w^{i, l}\right) \Longleftrightarrow p^{i} \geq \frac{(1-\phi)}{(1-\phi)+\phi(N-1)} .
\end{aligned}
$$

Likewise, to obtain the last inequality, we have substituted the posterior probabilities and have imposed $w^{i, l, *}=0$. Let us assume

$$
\frac{1}{N}<\phi
$$

$A 1$ implicitly requires that $\frac{\phi(N-1)}{(1-\phi)+\phi(N-1)}>\frac{1}{2}>\frac{(1-\phi)}{(1-\phi)+\phi(N-1)}$ holds and then the investor needs to take into account only the inequality given in Eq. (4). Intuitively, when the investor sees $p^{i}$ and it is larger than or equal to the threshold given in Eq. (4), the investor's threat of only going to court under a low claim and a high signal is credible. The reverse is true for any $\frac{1}{2} \leq p^{i}<\frac{\phi(N-1)}{(1-\phi)+\phi(N-1)}$. In this case it is not optimal for the investor to go to court in any case, the investor's threat of going to court is not credible, and the entrepreneur will always pretend to be unsuccessful. But then, the capital market breaks down, which is clearly inefficient. ${ }^{12}$ Consequently, the

\footnotetext{
12 We reach the same conclusion if accessing courts is costly but entrepreneurs are not forced to pay the investor her due returns when found guilty.
} 
entrepreneur maximization problem will be subject to the constraint given by Eq. (4). In Sect. 4.2 we will show that, under credible strategies, the optimal level of transparency should be more stringent and thus in equilibrium $p^{i}$ will be strictly larger than $\frac{1}{2}$.

We assume that (A2) always holds

$$
\phi<\frac{R(N-1) \alpha}{R(N-1) \alpha+(N-1)[F(N-\alpha)+R(1-\alpha) N]} .
$$

Let us concentrate on the more interesting case, that is, when the investor's threat to go to court is credible, so that the entrepreneur is taken to court only when his claim is low and the signal is high. ${ }^{13}$ The incentive compatibility constraint under low returns reads as follows:

$$
p^{i} w^{i, l}+\left(1-p^{i}\right) w^{i, l} \geq p^{i}\left\{w^{i, h}+[0-R N] k_{t}^{i}\right\}+\left(1-p^{i}\right)\left\{w^{i, h}+[0-R N] k_{t}^{i}\right\},
$$

where the RHS is the expected utility of the entrepreneur if he lies and claims a high return: given a realization of low returns, the signal would be low with probability $p^{i}$ and high with probability $1-p^{i}$. In both cases, by misreporting the entrepreneur receives the transfer $w^{i, h}$ and steals $[0-R N] k_{t}^{i}$. The LHS is the expected utility if he tells the truth, and it shows that with probability $1-p^{i}$ the return and the claim are both low but the signal is high, so the investor goes to court. However, since the entrepreneur is not guilty, he does not pay the penalty cost.

The inequality above can be rewritten as

$$
w^{i, l}-w^{i, h} \geq-R N k_{t}^{i}, \quad \forall i=1, \ldots, N
$$

Analogously, when the returns are high, the utility of the entrepreneur reporting the truth has to be higher than or equal to the utility if he lies

$$
\begin{aligned}
p^{i} w^{i, h}+\left(1-p^{i}\right) w^{i, h} \geq & p^{i}\left\{w^{i, l}+[R N-0] k_{t}^{i}-F k_{t}^{i}-[R N-0] k_{t}^{i}\right\} \\
& +\left(1-p^{i}\right)\left\{w^{i, l}+R N k_{t}^{i}\right\} .
\end{aligned}
$$

The RHS tells us that with probability $p^{i}$, the returns as well as the signal are high. Since the entrepreneur misreports with a low claim, he receives the transfer $w^{i, l}$ and steals $[R N-0] k_{t}^{i}$. But then the investor goes to court, the entrepreneur is caught lying, and he is forced to pay the penalty cost $F k_{t}^{i}$ as well as to pay back the investor her due returns. With probability $1-p^{i}$, the signal is high and the returns are low and the entrepreneur's claim is low, but the investor does not go to court. As a consequence, the entrepreneur receives $w^{i, l}$ and the diverted funds $[R N-0] k_{t}^{i}$. The ICH can be written as

13 If we assume that accessing courts is costless, investors will always take the entrepreneur to court whenever the claim is low and independently of the signal. As a result, in equilibrium, entrepreneurs will always tell the truth independently of $p^{i}$. Since this paper studies the determinants of transparency, this case loses importance. 


$$
w^{i, h}-w^{i, l} \geq\left[R N\left(1-p^{i}\right)-p^{i} F\right] k_{t}^{i}, \quad \forall i=1, \ldots, N .
$$

The next lemma shows that in equilibrium, the ICH is binding, and the ICL never binds. The intuition is clear: having no endowment, an entrepreneur is unable to misreport in the low state since that would entail surrendering a positive amount.

Lemma 1 In equilibrium, the incentive compatibility constraint under high returns is binding, while the incentive compatibility under low returns is not.

Proof The two IC conditions are $\left(R N\left(1-p^{i}\right)-p^{i} F\right) k_{t}^{i} \leq w^{i, h}-w^{i, l} \leq R N k_{t}^{i}$. Since the investor needs to induce truthful reporting, she tries to pay as little as possible under this condition. This is why the left inequality must be binding, which in turn implies that the right inequality is strict.

Proposition 1 specifies the equilibrium contingent transfer. Intuitively, what determines the entrepreneur's truthful reporting decision is the gap between wages, that is $w^{i, h}-w^{i, l}$, and not their absolute values. This implies that the representative investor wants to give the lowest possible payoff, which is zero given limited liability upon low realization, i.e. $w^{i, l}=0$, and the minimum incentive compatible reward upon high realization in order to prevent diversion, i.e. $w^{i, h}=\left(R N\left(1-p^{i}\right)-p^{i} F\right) k_{t}^{i}$.

Proposition 1 The optimal contract offered by the investor to an entrepreneur with $p^{i}$ induces truthful reporting and is given by:

$$
w^{i, l *}=0, \quad w^{i, h *}=\left(R N\left(1-p^{i}\right)-p^{i} F\right) k_{t}^{i} \text { for every } i=1, \ldots, N .
$$

Proof See Appendix.

The transfer per dollar invested decreases with $F$ and $p^{i}$. When either $F$ or $p^{i}$ are low, the entrepreneur can keep a higher amount of each dollar diverted. The optimal transfer intuitively predicts that when the cost of diversion is lower, the incentives needed to correct agency problems must be stronger, and thus the transfer will be higher.

The transfer needed to induce entrepreneurs' truthful behavior can also be interpreted as the informational cost of capital paid by the investors, or the cost of trading capital due to agency problems. When $F$ and $p^{i}$ are low, investor protection is low and thus the transfer per dollar invested from investor to entrepreneurs should increase. Therefore, a low level of investor protection leads to a high level of informational cost of capital. This finding is consistent with a number of theoretical papers showing that there is a negative correlation between investor protection and the cost of capital (see for instance, Castro et al. 2004; Himmelberg et al. 2004; Shleifer and Wolfenzon 2002). In their models, however, the story is different: when investor protection is perfect, managers optimally diversify fully idiosyncratic risk and steal nothing since insiders are risk averse. By contrast, under imperfect investor protection, insiders can credibly commit to lower rates of stealing by retaining a higher fraction of equity. Since they are forced to bear higher levels of diversifiable risk, risk sharing is not complete and thus the cost of capital increases. Their predictions are first, the weaker the investor 
protection, the higher the concentration of inside equity ownership; and second, the higher the concentration of inside ownership, the lower the degree of diversification and thus the higher the implied cost of capital.

The empirical evidence reported by Leuz and Verrecchia (2000) documents that firms' cost of capital decreases when they increase transparency. Similarly, Doidge et al. (2004) show that foreign firms with cross listings in the U.S., which are subject to higher accounting disclosure provisions than their foreign counterparts, have higher valuations and a lower cost of capital. ${ }^{14}$

Since higher levels of $p^{i}$ and $F$ lead to a higher level of investor protection, investors always prefer higher governance transparency and penalties to lower ones. In the extreme case of $F=0$ and the entrepreneur not being forced to pay back he due return to the investor, all the power would be in the entrepreneur's hands. The investor would therefore never have access to credible information and then there would be no sense in talking about the trade-off of the signal because there would no longer be informational rents. This shows a mutual connection between the elements of a country's institutional infrastructure and voluntary disclosure by the firm. ${ }^{15}$ Moreover, since the investor's preferences about the penalty $F$ are not aligned with those of the entrepreneurs, clearly if $F$ were part of the optimally chosen contract term, the penalty payment would always be strictly positive.

\subsection{Portfolio choice}

In what follows, we first analyze how the investor rationally formulates her portfolio decisions. Then we look at how governance disclosure affects the allocation of resources among the different firms.

The representative investor solves the following maximization problem

$$
\begin{aligned}
\operatorname{Max}_{\left\{c_{t},\left(k_{t}^{i}\right)_{1}^{N}, c_{t+1}\right\}} E\left(U_{t}\right) & =E_{t}\left(c_{t}^{1-\alpha} c_{t+1}^{\alpha}\right), \\
\text { subject to (3) \& } c_{t+1} & \leq y_{t+1}, \\
y_{t+1} & =R N k_{t}^{i}-w^{i, h *} \text { if } s^{i}, \text { with } i=1, \ldots N,
\end{aligned}
$$

where $s^{i}$ is when the state of nature $i$ occurs, which is the state where only firm $i$ succeeds and all others fail. The value of $w^{i, h *}$ is given by Proposition 1 . Define $\widetilde{p}=\frac{1}{N-1} \sum_{i \neq j} p_{t}^{i}$ as the average level of governance transparency of all other firms. The demand of capital for each risky firm is given by the next proposition.

\footnotetext{
${ }^{14}$ However, as Leuz and Wysocki (2008) point out, this line of research is still in its infancy and certainly needs to be validated through further empirical research.

15 If we assume that $F=0$ and the entrepreneur is forced to pay back the stolen returns, our main results apply but we cannot analyze how the strength of the legal system would affect the optimal level of transparency.
} 
Proposition 2 The optimal portfolio chosen by the representative investor in firm i is given by

$$
k_{t}^{i *}=\frac{\left(\frac{p^{i}}{\widetilde{p}}\right)^{\frac{\alpha}{1-\alpha}}}{(N-1)+\left(\frac{p^{i}}{\widetilde{p}}\right)^{\frac{\alpha}{1-\alpha}}} \alpha \bar{K}
$$

Proof See Appendix.

Other things being equal, the higher the quality of the signal in firm $i$, the higher the capital invested in this company. ${ }^{16}$ The rationale behind this result is clear: better transparency does pay. It cuts the costs of external financing, which results in a reallocation of resources from firms with a low level of transparency to more attractive firms characterized by more transparent financial accounting information. ${ }^{17}$ That is, our theory predicts that better governance transparency enables firms to access capital markets on better terms, which is valuable to firms intending to raise funds. Consistent with this idea, Rajan and Zingales (1998) find that firms in industries with significant needs for external financing, such as the pharmaceutical industry, grew substantially faster during the 1980s in countries with more demanding accounting-disclosure standards than firms in the same industries in countries with weak accounting-disclosure standards. Similarly, in a review of the empirical research on disclosure, Healy and Palepu (2001) report that voluntary disclosure policies are more often found in firms issuing new capital.

\subsection{Determinants of transparency}

Having characterized the optimal transfer and portfolio investment decisions, we are now in a position to take a step back and examine the driving forces behind governance transparency. The transfer ensuring no hiding along the equilibrium path, the stock of capital invested in the firm, and the minimum level of voluntary transparency that the investor is asking for, are the three key ingredients in solving the following entrepreneur problem,

$$
\begin{gathered}
\operatorname{Max}_{p^{i}} E\left(U^{i}\right)=\frac{1}{N}\left(R N\left(1-p^{i}\right)-p^{i} F\right) k_{t}^{i *}, \\
\text { subject to equations (7) \& (4) }
\end{gathered}
$$

\footnotetext{
16 Another channel by which transparency may affect capital markets is through changes in the equilibrium stock return. However, asset pricing is beyond the scope of this paper. For studies that incorporate the effect of agency cost on equilibrium asset prices see Albuquerque and Wang (2008) and Dow et al. (2005).

17 If the returns from the investment were heterogeneous across firms, financial accounting information would identify promising investment opportunities, meaning that financial capital would flow toward firms with prospects of high returns and away from sectors with poor prospects. This would lead directly to more efficient allocation of capital to the highest valued use.
} 
The next proposition first shows that even though the entrepreneur would like to divert cash flows ex-post, and transparency limits his ability to do so, he voluntarily chooses a strictly positive level of transparency ex-ante to be able to raise capital. The proposition also highlights the importance of not just a single variable when explaining its disclosure practices, but a range of variables related to the market structure of an industry, the enforcement of the law in the country as well as the firm's corporate profits.

Proposition 3 Under A2, the optimal level of voluntary governance transparency by the firm is given by

$$
p^{*}=\frac{R N}{R N+F}\left(\frac{\alpha(N-1)}{\alpha(N-1)+(1-\alpha) N}\right),
$$

with $1 / 2<p^{*}<1$. Moreover, the following comparative statics hold: $p^{*}$ is $(i)$ strictly increasing with the level of competition, $N$, (ii) strictly increasing with the level of corporate profits for the firm, $R$ and (iii) strictly decreasing with the weakness of the legal system, $F$.

\section{Proof See Appendix.}

Notice that in the good state, the optimal transfer is $w^{h *}\left(p^{*}\right)>0$, and then, consumption is positive for both investors and entrepreneurs. ${ }^{18}$ On the contrary, because limited liability constraints, $w^{l *}$ necessarily equals zero in the bad state. The model delivers several predictions.

First, the model demonstrates that, ceteris paribus, more product market competition leads to substantial improvements in voluntary transparency. In fact, as $N$ increases first, capital markets become more developed since more firms are seeking financing and thus the potential number of securities in an investor's portfolio increases. And second, the investment risk of each firm or project increases. Both effects together signify that there are more firms to invest in, but each one becomes less important on the optimal portfolio choice of investors overall, which in turn entails that the firm has less monopoly power. Hence, the only possibility firms have to attract more capital is to increase governance transparency.

In a recent empirical paper, Giroud and Mueller (2010) show that firms in noncompetitive industries experience a significant drop in operating performance after the passage of an anti-takeover law. By contrast, firms in highly competitive industries experience no significant effect, so managerial slack appears to increase only in non-competitive industries. In a subsequent paper, using the democracy-dictatorship hedge portfolio in Gompers et al. (2003), Giroud and Mueller (2011) find that the effect of governance on firms' operating performance, long-horizon stock returns or firm value is relatively small in competitive industries compared to non-competitive

\footnotetext{
18 That is, limited liability constraints $0 \leq w^{h *} \leq R N k_{t}^{i}$ are introduced but are not binding in the good state, i.e. $\left.\left[R N\left(1-p^{*}\right)-F p^{*}\right)\right] k_{t}^{i}<R N k_{t}^{i}$.
} 
industries, where governance matters more. Likewise, Guadalupe and Pérez-González (2006) find that product market competition is strongly negative correlated with private benefits of control. They also find that competition affects corporate governance by increasing the quality of information available to investors and by increasing the default probability. ${ }^{19}$

Although these empirical papers find a positive link between product market competition and corporate governance, this is not a direct test of the model proposed here. First, because they do not focus on firms' disclosure measures and financial reporting standards; and second, because none of them assess our proposed disciplining forces that competition imposes on the governance disclosure decisions of firms. Clearly, more research on this subject would be useful to validate the importance of our theory.

Second, the stronger the legal system, the lower the level of governance transparency. The exogenous penalty cost $F$ reflects the effectiveness of a country's legal system; a higher penalty cost when an entrepreneur is found guilty means better investor protection. It is worth noting that our theory does not attempt to claim that quality accounting is a replacement for country-level legal reform. Rather, the model suggests that firms in countries with poor investor protection can improve it by adopting better accounting standards.

In general, it is not clear whether a country-level legal infrastructure and voluntary governance transparency will act as substitutes or complements. One possibility is that firms in countries with weak laws would want to adopt better governance transparency to counterbalance the weaknesses in their country's legal system and signal their intention to ensure greater investor rights. This would suggest a negative correlation between governance transparency and country-level laws. By contrast, a second possibility is that in countries with weak laws, governance transparency would tend to be lower.

On the empirical side, this relationship of substitutability between the strength of the legal system and firm-level corporate governance and disclosure rankings is in line with the empirical evidence of Klapper and Love (2004), Durnev and Kim (2005) and Bruno and Claessens (2010). Similarly, using a modification of Shleifer and Wolfenzon (2002)'s model, Doidge et al. (2004) show that although country-level governance is an important determinant of firm-level corporate governance, when firms have access to global capital markets, country characteristics matter less in explaining the quality of governance practices at the firm level. Baht et al. (2006) and Bushman et al. (2004) show the same results using governance transparency measures. Leuz et al. (2003) and Ball et al. (2000) suggest that the quality of financial accounting information is limited instead by institutional factors. As far as we know, there is little empirical work on this issue and further research would help us to understand the interactions between institutional laws at the country level and voluntary governance transparency by the firm.

Third, our theory also shows that the degree of corporate profits may shape the degree of voluntary transparency. When corporate profits are high, agency problems become significant because the entrepreneur has more incentives to expropriate. As a result, the firm would find it optimal to impose ex-ante stricter governance

19 For an empirical analysis of how product market competition affects incentives contract through executive compensation packages see, for example, Cuñat and Guadalupe (2009). 
regulation mechanisms as a commitment device to prevent ex-post expropriation. Hermalin (2008) also concludes that there is a positive correlation between quality of governance and corporate performance. In his theoretical model, like us, firm value determines the level of corporate governance. Unlike us, there is firm heterogeneity in marginal returns to resources. Firms with greater marginal returns raise higher external financing and thus have stronger corporate governance, which in turn increases profits.

Our third result is in line with the work of Himmelberg et al. (1999), who argue that some firms find it easier to expropriate from minority shareholders due to the nature of their operations. For example, the composition of a firm's assets will affect its contracting environment because it is easier to monitor and harder to steal fixed assets (i.e., machinery and equipment) than "soft" capital (i.e., intangibles, R\&D capital, and short-term assets, such as inventories). Therefore, firms operating with higher proportions of intangible assets may find it optimal to adopt higher governance transparency to signal to investors that they intend to prevent the future misuse of these assets.

The empirical work of Gompers et al. (2003) and Klapper and Love (2004) shows a positive and strong correlation between corporate governance at the firm level and firms' operating performance. Because of data limitations, however, they do not analyze the causality issues in depth. Gompers et al. (2003) construct a governance index to proxy for shareholders rights whereas the governance score of Klapper and Love (2004) reports data over seven broad categories measuring management discipline, transparency, independence, accountability, responsibility and fairness. The present paper demonstrates that if we focus only on governance disclosure, the causality between transparency and firm performance could go in the opposite direction instead.

Since profits increase during an upswing and decrease during a recession, our analysis would suggest that it is during economic upturns that we need greater governance vigilance. This is so because agency problems increase during economic upturns, and thus we would find that the quality of governance needs to be improved in a boom. $^{20}$

Overall, the study of the determinants of governance transparency shows us a bottom line history: firms for whom access to capital markets is important have incentives to signal their intentions to offer higher quality of information. Transparency then acts as a disciplining device, and markets are likely to reward those firms that opt for this type of commitment device. These findings are consistent with the hypothesis that one of the main roles of publicly reported financial accounting information in corporate governance is to protect external financiers.

\subsection{Discussion of modeling assumptions}

The results of this study are based on a reduced form model involving a number of strong assumptions. We noted in a number of places throughout the article that many of our results are quite robust to the model specifications. However, this study is subject

\footnotetext{
20 For papers that study business cycle variation in the degree of corporate control friction see Philippon (2006) and Dow et al. (2005).
} 
to several shortcomings. One clear example is the assumption of the winner takes-it-all type of competition. Specifically, we consider $N$ firms endowed with a risky project. In the case of success, only one firm gets the profit of all market $R N$, which occurs with probability $\frac{1}{N}$, whereas the other $N-1$ firms fail with probability $1-\frac{1}{N}$ and the realized return is zero. The assumption of competition of the winner takes-it-all type leads to the perfectly negative correlation of output outcomes. Therefore, investing in a risky firm is equivalent to buying a basic Arrow security that pays in only one state of nature (i.e. an investment of $k_{t}^{i}$ units of capital in firm $i$ pays the amount $R N k_{t}^{i}$ if firm $i$ succeeds with probability $\frac{1}{N}$ and nothing otherwise). ${ }^{21}$ Under this assumption we can have a closed solution for the portfolio choice and consequently, for the optimal level of transparency. Another implication of this assumption is that the larger the number of firms in the market, i.e. large $N$, the more firms will seek funding. In this case, however, investors will change their behavior in order to reduce their risk in such a way that fewer resources will be invested in each firm.

The assumption of perfectly negative correlation of output may be hard to rationalize empirically. Yet the idea behind it is that most economies have access to a large number of imperfectly correlated risky projects and thus a significant part of the risk investors face can be diversified. In developed economies in particular, diversification opportunities are better since more risky projects are available to investors. In developing countries, by contrast, it is more likely that the existence of, for example, a minimum requirement scale or a fixed cost for opening a firm would imply that not all risky projects are available, thereby reducing the diversification opportunities. Therefore, the assumption of imperfectly correlated risky projects fits better for developed economies. In fact, one stylized fact relating diversification and growth is that less developed countries are more volatile than more developed ones. ${ }^{22}$

Note that in our paper, entrepreneurs can be taken to court ex-post by investors with the court providing assurance about the quality of firms's disclosures. Alternatively, investors can write an ex-ante contract specifying for example when the investor is going to court or when to audit a borrower who fails to meet contractual obligations. The costly state verification literature concentrates on this second mechanism (see, for example, Townsend 1979; Gale and Hellwig 1985). Like us, Townsend (1979) and Gale and Hellwig (1985), analyze a framework of asymmetric information where the returns on a project are random and not observable by some agents. In their papers the lender cannot observe the returns unless the lender undertakes an audit, which is costly. The contract has to specify when an audit will be undertaken and how its result will affect the payment to the lender. In our paper, however, the decision on whether or not to go to court is based on both the claim and the signal. This is the reason why the investor updates her beliefs. If the decision to go to court were specified ex-ante, posterior probabilities would no longer be needed and, qualitatively, the results would not change.

\footnotetext{
21 We have a total of $N$ equally likely states of nature where in each state one firm succeeds with probability $\frac{1}{N}$, and fails with probability $1-\frac{1}{N}$. For instance, since we have $N$ firms confronted with independent risk, and only one firm succeeds, offering $N$ contracts generates the same diversification as a $2^{N}$ contingent market would.

22 See for example Koren and Tenreyro (2007).
} 


\section{Conclusions}

This paper develops a theoretical model of corporate transparency of firms, treating governance disclosure as endogenous. The optimal level of transparency is chosen by an entrepreneur raising capital in financial markets. The central trade-off when deciding the quality of governance transparency is that higher quality information increases the possibility of expropriating a larger share of the profits against the opportunity to raise more capital in financial markets. The paper shows that, to incentivize a legal action, investors need a certain threshold of quality of information, otherwise, investors cannot credible commit and thus the capital market will break down. If, by contrast, the quality of information is high enough, although entrepreneurial diverted funds are zero in equilibrium, the optimal level of disclosure is far from perfect.

Furthermore, our theory indicates the driving forces of voluntary transparency and helps us predict which firms are likely to engage in strategies to avoid a proposed regulation. Indeed, tougher competition in the product market, a weak legal system or a higher level of corporate profits are variables that increases governance transparency.

Our results have several policy implications. According to our theory, firms in a setting of high industry concentration or where the financial markets are not developed would be more likely to lobby against voluntary disclosure regimes because diversification would be more difficult to achieve. Indeed, we would expect that if policy makers concentrated their efforts on improving product market competition and capital markets, then financial transparency would increase as well. ${ }^{23}$ Finally, we have also found that information is only valuable (that is, transactions occur and transparency solves the agency problem) if enough of it is disclosed. Therefore, another policy implication is that regulating disclosure by requiring a minimal precision level for the disclosures could be welfare improving.

Our model is one shot game involving one period of disclosure followed by one transaction. It would be interesting to study the issues addressed in this paper in a rich framework. For example, by studying the process of governance transparency in a dynamic setting, the role of reputation and credibility issues as mechanisms for solving information problems would provide further insights. Finally, and equally importantly, the proposed theory opens the door to new research on empirical issues of voluntary governance transparency, by testing the new mechanisms suggested in the paper, and proposing new control variables to examine determinants of firm-level disclosure in large cross-sectional data sets.

\section{Appendix}

Proof of Proposition 1 First, to induce the incentive for truthful reporting, the investor only needs to ensure that the wage difference $w^{i, h *}-w^{i, l *}$ satisfies

\footnotetext{
${ }^{23}$ For example, by enacting laws to make markets more competitive, and by promoting financial intermediation.
} 
$\left(R N\left(1-p^{i}\right)-p^{i} F\right) k_{t}^{i} \leq w^{i, h}-w^{i, l} \leq R N k_{t}^{i}$. Hence, the investor's utility maximization implies $w^{i, l *}=0$.

Second, if the investor pays $w^{i, h *}>R N k_{t}^{i}$, the entrepreneur will lie when output is low. If so, the investor will compute her ex-ante expected future income before signing the contract as

$$
\begin{aligned}
& \frac{1}{N}\left[p^{i}\left(R N k_{t}^{i}-w^{i, h *}\right)+\left(1-p^{i}\right)\left(R N k_{t}^{i}-w^{i, h *}\right)\right] \\
& \quad+\left(1-\frac{1}{N}\right)\left[p^{i}\left(R N k_{t}^{i}-w^{i, h *}\right)+\left(1-p^{i}\right)\left(R N k_{t}^{i}-w^{i, h *}\right)\right] \\
& =R N k_{t}^{i}-w^{i, h *}<0 .
\end{aligned}
$$

Hence, the investor will not pay $w^{i, h *}>R N k_{t}^{i}$. The other possibility is that the investor may choose to pay $w^{i, h *}<\left(R N\left(1-p^{i}\right)-p^{i} F\right) k_{t}^{i}$. If so, the entrepreneur will lie when output is high. And thus, the investor's expected income in the second period is

$$
\begin{aligned}
& \frac{1}{N}\left[p^{i}\left(0-w^{i, l *}\right)+\left(1-p^{i}\right)\left(0-w^{i, l *}\right)\right] \\
& \quad+\left(1-\frac{1}{N}\right)\left[p^{i}\left(0-w^{i, l *}\right)+\left(1-p^{i}\right)\left(0-w^{i, l *}\right)\right] \\
& =-w^{i, l *}=0,
\end{aligned}
$$

Hence, the investor has no incentive to pay $w^{i, h *}<\left(R N\left(1-p^{i}\right)-p^{i} F\right) k_{t}^{i}$. Note that even when $w^{i, h *}=0$, the incentive compatible contract is not in place and the firm will always optimally claim low returns realization. This implies that, whatever the outcome of the returns, the investor's expected income in the second period will always be equal to zero.

Instead, if the investor chooses to pay $w^{i, h *}=\left(R N\left(1-p^{i}\right)-p^{i} F\right) k_{t}^{i}$, her expected income is

$$
\begin{gathered}
\frac{1}{N}\left[p^{i}\left(R N k_{t}^{i}-w^{i, h *}\right)+\left(1-p^{i}\right)\left(R N k_{t}^{i}-w^{i, h *}\right)\right] \\
\quad+\left(1-\frac{1}{N}\right)\left[p^{i}\left(-w^{i, l *}\right)+\left(1-p^{i}\right)\left(-w^{i, l *}\right)\right] \\
=\frac{1}{N}\left(R N k_{t}^{i}-w^{i, h *}\right)=\frac{1}{N} p^{i}(R N+F) k_{t}^{i}>0 .
\end{gathered}
$$

Observe that investor's expected income is increasing with the level of corporate governance at the firm and at the country level (i.e. $p^{i}$ and $F$ ). The larger these values, the larger her bargaining power is.

Proof of Proposition 2 Plugging the budget constraint into the utility function, the utility function may be rearranged as $U_{t}=c_{t}^{1-\alpha}\left[V\left(k_{t}^{1}, ., k_{t}^{i}, . ., k_{t}^{n}\right)\right]^{\alpha}$ where $V$ is a sub-utility function which is defined over a potentially large amount of capital invested in each of the $N$ firms, $k_{t}^{i}$. The expected utility of the representative risk-averse investor becomes 


$$
E\left(U_{t}\right)=\left[\bar{K}-\sum_{i=1}^{N} k_{t}^{i}\right]^{1-\alpha}\left[\sum_{i=1}^{N} \frac{1}{N}\left(\left(R N-x^{i}\right) k_{t}^{i}\right)^{\alpha}\right],
$$

where $x^{i}=R N\left(1-p^{i}\right)-p^{i} F$ is the transfer per unit of capital paid by the representative investor to the firm to induce him not to lie. Note that $\sum_{i=1}^{N} \frac{1}{N}\left(\left(R N-x^{i}\right) k_{t}^{i}\right)^{\alpha}$ denotes the expected consumption of period $t+1$ over the $N$ states of nature. In each state, which is equally likely with probability $\frac{1}{N}$, only one firm succeeds.

The investor has to choose: (i) how to divide the total stock of capital between consumption for the first period and savings and (ii) how to divide the amount of capital invested $K_{t}$ among the $N$ different projects available on the financial market (i.e. choosing $k_{t}^{i} \forall i=1, \ldots N$ ).

Step 1 Choose between consumption and savings.

Remark 1 Since all firms are symmetric, $w^{i, h *}=w \forall i=1, \ldots N$. The expected utility may then be rewritten as

$$
E(U)=\left[\bar{K}-\sum_{i=1}^{N} k_{t}^{i}\right]^{1-\alpha}(R N-x)^{\alpha} \frac{1}{N}\left[\sum_{i=1}^{N}\left(k_{t}^{i}\right)^{\alpha}\right]
$$

Remark 2 Since we have ex ante homogenous firms, we know that in equilibrium $k_{t}^{i}=k_{t} \forall i=1, \ldots N$. Therefore, $\sum_{i=1}^{N} k_{t}^{i}=N k_{t}=K_{t}$, which implies that $k_{t}=\frac{K_{t}}{N}$. Then, $\sum_{i=1}^{N} \frac{1}{N}\left(k_{t}^{i}\right)^{\alpha}=\frac{N}{N} k_{t}^{\alpha}=\left(\frac{K_{t}}{N}\right)^{\alpha}$.

The investor problem can be rewritten as

$$
\begin{aligned}
& \operatorname{Max}_{K_{t}} E(U)=\left[\bar{K}-K_{t}\right]^{1-\alpha} \frac{1}{N}(R N-x)^{\alpha} N^{-\alpha} K_{t}^{\alpha} . \\
& F O C: \quad \frac{\partial U}{\partial K_{t}}=0 \Longleftrightarrow(1-\alpha) K_{t}-\alpha\left[\bar{K}-K_{t}\right]=0 \Longleftrightarrow K_{t}^{*}=\alpha \bar{K} .
\end{aligned}
$$

Note that $K_{t}^{*}$, which is the saving rule, is proportional to the endowment of capital, and $c_{t}^{*}=(1-\alpha) \bar{K}>0$.

Step 2 Portfolio allocation decision: choose $k_{t}^{i} \forall i=1, \ldots N$.

The investor's problem is given by

$$
\begin{aligned}
& \operatorname{Max}_{k_{t}^{i}} E(U)=[(1-\alpha) \bar{K}]^{1-\alpha} \frac{1}{N}\left[\left(k_{t}^{i}\right)^{\alpha}\left(R N-x^{i}\right)^{\alpha}+\sum_{i=1}^{N-1}\left(k_{t}^{i}\right)^{\alpha}\left(R N-x^{i}\right)^{\alpha}\right] \\
& \text { s.t. } \sum_{i=1}^{N} k_{t}^{i}=\alpha \bar{K} .
\end{aligned}
$$

Remark 1 In equilibrium all firms are symmetric and then $x^{i}=x \forall i=1, \ldots N$. Define $\widetilde{x}=\frac{1}{N-1} \sum_{i \neq j} x^{i}$. 
Remark 2 In equilibrium $k_{t}^{i}=k_{t} \forall i=1, \ldots N$. Therefore, $\sum_{i=1}^{N-1} k_{t}^{i}=(N-1) k_{t}=$ $\alpha \bar{K}-k_{t}^{i}$, and thus $k_{t}=\frac{\alpha \bar{K}-k_{t}^{i}}{N-1}$. Or similarly, $\sum_{i=1}^{N-1}\left(k_{t}^{i}\right)^{\alpha}=(N-1)\left(\frac{\alpha \bar{K}-k_{t}^{i}}{N-1}\right)^{\alpha}=$ $(N-1)^{1-\alpha}\left(\alpha \bar{K}-k_{t}^{i}\right)^{\alpha}$.

The maximization problem could be rewritten as

$$
\begin{aligned}
& \operatorname{Max}_{k_{t}^{i}} E(U)=[(1-\alpha) \bar{K}]^{1-\alpha} \frac{1}{N}\left[\left(k_{t}^{i}\right)^{\alpha}\left(R N-x^{i}\right)^{\alpha}\right. \\
& \left.+(R N-\tilde{x})^{\alpha}\left(\alpha \bar{K}-k_{t}^{i}\right)^{\alpha}(N-1)^{1-\alpha}\right] . \\
& \text { FOC: } \frac{\partial U}{\partial k_{t}^{i}}=0 \Longleftrightarrow\left(k_{t}^{i}\right)^{\alpha-1}\left(R N-x^{i}\right)^{\alpha}=(R N-\widetilde{x})^{\alpha}\left(\alpha \bar{K}-k_{t}^{i}\right)^{\alpha-1}(N-1)^{1-\alpha} \text {, } \\
& k_{t}^{i *}=\frac{\left(\frac{R N-x^{i}}{R N-\widetilde{x}}\right)^{\frac{\alpha}{1-\alpha}}}{(N-1)+\left(\frac{R N-x^{i}}{R N-\widetilde{x}}\right)^{\frac{\alpha}{1-\alpha}}} \alpha \bar{K}=\frac{\left(\frac{p^{i}}{\widetilde{p}^{j}}\right)^{\frac{\alpha}{1-\alpha}}}{(N-1)+\left(\frac{p^{i}}{\widetilde{p}^{j}}\right)^{\frac{\alpha}{1-\alpha}}} \alpha \bar{K},
\end{aligned}
$$

where the last equality was obtained taking into account $x^{i}=R N\left(1-p^{i}\right)-p^{i} F$ and $\widetilde{x}=R N(1-\widetilde{p})-\widetilde{p} F$, where $\widetilde{p}=\frac{1}{N-1} \sum_{i \neq j} p^{i}$.

Proof of Proposition 3 The optimal level of voluntary transparency can be obtained by maximizing the Lagrangian given by,

$$
\begin{aligned}
L\left(p^{i}, \lambda\right) & =\frac{1}{N}\left(R N\left(1-p^{i}\right)-p^{i} F\right) k_{t}^{i *}+\lambda\left\{p^{i}-\frac{\phi(N-1)}{(1-\phi)+\phi(N-1)}\right\} \\
\frac{\partial L}{\partial p^{i}} & =0 \Leftrightarrow \frac{1}{N}(-1)[R N+F] k_{t}^{i *}+\frac{1}{N}\left(R N\left(1-p^{i}\right)-p^{i} F\right) \frac{\partial k_{t}^{i *}}{\partial p^{i}}+\lambda=0, \\
\frac{\partial L}{\partial \lambda} & \geq 0, \lambda \geq 0, \lambda \frac{\partial L}{\partial \lambda}=0,
\end{aligned}
$$

where $\lambda$ denotes the Lagrange multiplier associated with the minimum level of transparency the investor is asking for (i.e. Eq. (4)).

Case (a) Let us assume $\lambda=0$, then $\frac{\partial L}{\partial p^{i}}=0$ becomes

$$
[R N+F] k_{t}^{i *}=\left(R N\left(1-p^{i}\right)-p^{i} F\right) \frac{\partial k_{t}^{i *}}{\partial p^{i}}
$$

The return per dollar invested is $R N\left(1-p^{i}\right)-p^{i} F$ and it is multiplied by $\frac{\partial k_{t}^{i *}}{\partial p^{i}}$ which measures the marginal effect on $k_{t}^{i *}$ of increasing voluntary transparency. Therefore, Eq. (9) tells us that the optimal level of voluntary disclosure of information is given when the marginal cost of better governance equals the marginal revenues from increasing an additional unit of governance transparency. Since $p^{i}=p \forall i=1, \ldots N$, the equation above becomes $p^{i}\left(1+\frac{\alpha}{1-\alpha} \frac{N-1}{N}\right)(R N+F)=R N \frac{\alpha}{1-\alpha} \frac{N-1}{N}$, and thus the optimal value of $p^{*}$ is

$$
p^{*}=\frac{R N}{R N+F}\left(\frac{(N-1) \alpha}{(N-1) \alpha+(1-\alpha) N}\right)
$$


Notice that if A2 holds, then for sure $p^{*}>\frac{\phi(N-1)}{(1-\phi)+\phi(N-1)}$ also holds for sure.

Case (b) assumes that the Eq. (4) binds and thus the candidate solution is $p^{i *}=$ $\frac{\phi(N-1)}{(1-\phi)+\phi(N-1)}$. But then, $\lambda=\frac{1}{N} k_{t}^{i *}\left[(R N+F)-\left(R N\left(1-p^{i *}\right)-p^{i *} F\right) \frac{\alpha}{1-\alpha} \frac{N-1}{N} \frac{1}{p^{i *}}\right]<0$ since by A2 the expression in brackets is negative. Consequently, $p^{i *}=\frac{\phi(N-1)}{(1-\phi)+\phi(N-1)}$ cannot be the solution.

Note that $p^{*}$ needs to be a number between $\frac{1}{2}$ and 1 . Since $\frac{R N}{R N+F}<1$ and $\frac{\alpha(N-1)}{\alpha(N-1)+(1-\alpha) N}<1$, transparency is far from perfect in equilibrium. Moreover $p^{*}$ is strictly larger than $\frac{1}{2}$ because first A1 leads to $\frac{1}{2}<\frac{\phi(N-1)}{(1-\phi)+\phi(N-1)}$ and second A2 ensures that Eq. (4) does not bind. Therefore, $\frac{1}{2}<\frac{\phi(N-1)}{(1-\phi)+\phi(N-1)}<p^{*}<1$ holds in equilibrium. Furthermore, it is easy to check that $w^{i, h *}>0$. Finally, assumptions A2 and A2 imply that $\frac{1}{N}<\phi<\frac{R(N-1) \alpha}{R(N-1) \alpha+(N-1)[F(N-\alpha)+R(1-\alpha) N]}$, and since $p^{*}$ is strictly larger than $\frac{1}{2}$, the following inequality always hold $\frac{1}{N}<$ $\frac{R(N-1) \alpha}{R(N-1) \alpha+(N-1)[F(N-\alpha)+R(1-\alpha) N]}$.

Open Access This article is distributed under the terms of the Creative Commons Attribution License which permits any use, distribution and reproduction in any medium, provided the original author(s) and source are credited.

\section{References}

Adams R, Ferreira D (2007) A theory of friendly boards. J Financ 62(1):217-250

Admati AR, Pfleiderer P (2000) Forcing firms to talk: financial disclosure regulation and externalities. Rev Financ Stud 13(3):479-519

Albuquerque R, Wang N (2008) Agency conflicts, investment, and asset pricing. J Financ 69(1):1-40

Allen F, Gale D (2000) Corporate governance and competition. In: Vives X (ed) Corporate governance. Cambridge University Press, Cambridge

Baht G, Hope O-K, Kang T (2006) Does corporate governance transparency affect the accuracy of analyst forecasts? Account Financ 46:715-732

Ball R, Kothari SP, Robin A (2000) The effect of international institutional factors on properties of accounting earnings. J Account Econ 29:1-51

Bruno V, Claessens S (2010) Corporate governance and regulation: can there be too much of a good thing? J Financ Intermed 19(4):461-482

Bushman RM, Piotroski JD, Smith AJ (2004) What determines corporate transparency? J Account Res 42:207-252

Castro C, Clementi G, McDonald G (2004) Investor protection, optimal incentives and economic growth. Q J Econ 119(3):1131-1175

Cuñat V, Guadalupe M (2009) Executive compensation and competition in the banking and financial sectors. J Bank Financ 33:439-474

Doidge C, Andrew Karolyi G, Stulz RM (2004) Why are foreign firms listed in the U.S. worth more? J Financ Econ 71:205-238

Doidge C, Andrew Karolyi G, Stulz RM (2007) Why do countries matter so much for corporate governance? J Financ Econ 86(1):1-39

Dow J, Gorton G, Krishnamurthy A (2005) Equilibrium investment and asset prices under imperfect corporate control. Am Econ Rev 95(3):659-681

Durnev A, Kim EH (2005) To steal or not to steal: firm attributes, legal environment, and valuation. J Financ 60(3):1461-1493

Enriques L, Volpin P (2007) Corporate governance reforms in continental Europe. J Econ Perspect 21(1):117-140 
Gale D, Hellwig M (1985) Incentive-compative debt contracts: the one-period problem. Rev Econ Stud 52(4):647-663

Giroud X, Mueller HM (2010) Does corporate governance matter in competitive industries? J Financ Econ 95(3):312-331

Giroud X, Mueller HM (2011) Corporate governance, product market competition, and equity prices. J Financ 66(2):563-600

Gompers P, Ishii JL, Metrick A (2003) Corporate governance and equity prices. Q J Econ 118:1076-1155

Guadalupe M, Pérez-González F (2006) Competition and private benefits of control. AFA 2007 Chicago Meetings Paper. SSRN: http://ssrn.com/abstract=890814

Hart OD (1983) The market mechanism as an incentive scheme. Bell J Econ 14:366-382

Healy P, Palepu K (2001) Information asymmetry, corporate disclosure, and the capital markets: a review of the empirical disclosure literature. J Account Econ 31:405-440

Hermalin BE (2008) Firm value and corporate governance: does the former determine the latter? UC Berkeley, Working Paper Series

Hermalin BE, Weisbach MS (2008) Information disclosure and corporate governance. J Financ (forthcoming)

Himmelberg C, Hubbard RG, Palia D (1999) Understanding the determinants of managerial ownership and the link between ownership and performance. J Financ Econ 53:353-384

Himmelberg C, Hubbard RG, Love I (2004) Investor protection, ownership and the cost of capital. World Banks Policy Research Working paper no 2834

Holmström Bengt R, Tirole J (1989) The theory of the firm. In: Schmalensee R, Willig RD (eds) Handbook of industrial organization, vol I. Elsevier, Amsterdam

Innes R (1990) Limited liability and incentive contracting with ex-ante action choices. J Econ Theory 52:45-67

Klapper LF, Love I (2004) Corporate governance, investor protection, and performance in emerging markets. J Corp Financ 10(5):703-728

Koren M, Tenreyro S (2007) Volatility and development. Q J Econ 122(1):243-287

Leuz C, Verrecchia RE (2000) The economic consequences of financial reporting and disclosure regulation. J Account Res 38:91-124

Leuz C, Wysocki P (2008) Economic consequences of financial reporting and disclosure regulation: a review and suggestions for future research. SSRN: http://ssrn.com/abstract=1105398

Leuz C, Nanda D, Wysocki P (2003) Investor protection and earnings management: and international comparison. J Financ Econ 69:505-527

Mata J, Portugal P, Gimaraes P (1995) The survival of new plants: start-cost conditions and post-entry evolution. Int J Ind Organ 13(4):459-481

Philippon T (2006) Corporate governance over the business cycle. J Econ Dyn Control 30:2117-2141

Rajan R, Zingales L (1998) Financial development and growth. Am Econ Rev 88(3):559-586

Scharfstein D (1988) Product-market competition and managerial slack. Rand J Econ 19:147-155

Shleifer A, Vishny RW (1997) A survey of corporate governance. J Financ 52:737-783

Shleifer A, Wolfenzon D (2002) Investor protection and equity markets. J Financ Econ 66(1):3-27

Song F, Thakor AV (2006) Information control, career concerns, and corporate governance. J Financ 61(4):1845-1896

Stigler G (1958) The economies of scale. J Law Econ 1:54-71

Stiglitz J (1985) Credit markets and the control of capital. J Money Credit Bank 17:133-152

Townsend R (1979) Optimal contracts and competitive markets with costly state verification. J Econ Theory 21(2):265-293

Vives X (2000) Corporate governance: does it matter? In: Vives X (ed) Corporate governance. Cambridge University Press, Cambridge 